\title{
EFFECTIVENESS OF LAPAROSCOPIC SUTURING VERSUS CLIP APPLICATION IN CHOLECYSTECTOMY- OUR EXPERIENCE
}

\author{
Ashok Y. Kshirsagar1, Aditya Chawla²
}

1 Professor, Department of General Surgery, Krishna Institute of Medical Sciences, Karad, Maharashtra, India.

${ }^{2}$ Resident, Department of General Surgery, Krishna Institute of Medical Sciences, Karad, Maharashtra, India.

\begin{abstract}
BACKGROUND
ABSTRACT

Laparoscopic cholecystectomy (LC) has become the gold standard treatment for symptomatic gall stone disease. Post cholecystectomy bile leak occurs mostly because of extra-hepatic bile duct injuries. It is a rare but potentially disastrous complication associated with significant morbidity and mortality, increase in healthcare expenses, and also is the commonest reason for medical litigation in gastrointestinal surgery. We wanted to compare the overall operative time of suture ligation with that of LIGACLIPs.
\end{abstract}

\section{METHODS}

A retrospective analysis of records of all patients who underwent cholecystectomy from January 2016 to December 2016 at Krishna Institute of Medical Sciences, was conducted in July 2018. KIMS is a referral tertiary level teaching hospital in Karad, Maharashtra.

\section{RESULTS}

The mean operative time in group A was 30-50 minutes and in group B it was 30-40 minutes ( $\mathrm{p}=0.015)$. The time required for suture ligation was $6.5 \pm 1.3 \mathrm{~min}$ and for LIGACLIPs it was only $4 \pm 1.1 \mathrm{~min}$ thus decreasing the overall operative time of the procedure $(\mathrm{p}>0.001)$ which was significant.

\section{CONCLUSIONS}

We observed that silk suture is safe, cost effective but it required training as compared to clip application. But for clip application, clip applicator is required, which is costly.

HOW TO CITE THIS ARTICLE: Kshirsagar AY, Chawla A. Effectiveness of laparoscopic suturing versus clip application in cholecystectomy- our experience. J. Evolution Med. Dent. Sci. 2019;8(19):1592-1594, DOI: 10.14260/jemds/2019/352

\section{BACKGROUND}

Laparoscopic cholecystectomy (LC) has become the gold standard treatment for symptomatic gall stone disease. Post cholecystectomy bile leak occurs mostly because of extrahepatic bile duct injuries. It is a rare but potentially disastrous complication associated with significant morbidity and mortality, increase in healthcare expenses, and also is the commonest reason for medical litigation in gastrointestinal surgery. ${ }^{1}$

However, the incidence rate of bile duct injury (BDI) has risen from $0.06 \%$ to $0.3 \%$. Open cholecystectomy has risen from $0.5 \%$ to $1.4 \%$ when gallbladder removal is performed laparoscopically.2-12 In initial studies on the removal of laparoscopic gallbladder, complications such as bleeding, wound infection, respiratory insufficiency, trocar injury to the intra-abdominal viscera, major vascular injury, and bile leaking accounted for reported morbidity rate ranging from $1.0 \%$ to $8.0 \% .^{2-8}$

Despite the completion of the learning curve and the recognition of preventive manoeuvres to avoid ductal injury during laparoscopic cholecystectomy, the incidence rate of BDI remains unchanged. ${ }^{13}$ In addition, injuries of the bile duct

'Financial or Other Competing Interest': None.

Submission 05-03-2019, Peer Review 22-04-2019,

Acceptance 30-04-2019, Published 13-05-2019.

Corresponding Author:

Dr. Aditya Chawla,

Department of General Surgery,

Krishna Institute of Medical Sciences,

Karad, Satara-415110, Maharashtra, India.

E-mail: researchexpert3@gmail.com

DOI: $10.14260 /$ jemds $/ 2019 / 352$ system after laparoscopic cholecystectomy are more complex than that after an open approach, causing significant morbidity and even death. Associated vascular lesions, particularly injuries to the right hepatic artery or longitudinal strictures of the common bile duct due to failed repair attempts, are not uncommon.

The laparoscopic surgery requires adequate methods for securing haemostasis and closure of tubular structure such cystic duct stump during laparoscopic cholecystectomy. During laparoscopic cholecystectomy, it is necessary to occlude cystic duct permanently in order to prevent bile flow into the peritoneal cavity. Traditionally this has been through the application of non-absorbable titanium metal clips. Disadvantages are interference with imaging techniques such as MRI and CT scan.

Suturing have been suggested as alternatives. Recently ultrasonic dissectors have been used to occlude the cystic duct. Concerns about the use of these alternatives include slipping of suture and concerns about their efficacy in the prevention of bile leak from the cystic duct stump. Disadvantages are operating time is also longer when suturing were used for occlusion of cystic duct.

\section{METHODS}

A retrospective analysis of records of all patients who underwent cholecystectomy from January 2016 to December 2016 at Krishna instate of medical science was conducted in July 2018. KIMS is a referral tertiary level teaching hospital in Karad, Maharashtra. The hospital accepts referrals and walking emergency conditions from everywhere. Operation Theatre log book and individual. With the help of hospital 
records, Patients in whom cystic pedicle was ligated using suture were assigned group A (60 cases), and the one in whom LIGACLIPs were used were named under group B (60 cases). Records of all the known and operated cases of chronic cholecystitis with cholelithiasis were included in the present study.

Patients complicated with perforated gallbladder, empyema gallbladder, common bile duct stones, acute abdomen, bleeding disorders, pregnancy and those patients not fit for surgery were excluded.

\section{RESULTS}

Hospital record of total number of 120 patients operated for cholecystectomy were selected in the present study. Patients in whom cystic pedicle was ligated using suture were assigned group A (60 cases), and the one in whom LIGACLIPs were used were named under group B (60 cases). In group A, there were 24 males and 36 females, whereas in group B there were 23 males and 37 females. Both groups had cholelithiasis and acute attack was excluded using history, clinical examination and pre-operative imaging. Patients in whom cystic pedicle was ligated using suture were assigned group $\mathrm{A}$, and the one in whom LIGACLIPs were used were named under group B. The mean operative time in group $\mathrm{A}$ was 30-50 minutes and in group $B$ it was $30-40$ minutes $(\mathrm{p}=$ 0.015 ). The time required for suture ligation was $6.5 \pm 1.3 \mathrm{~min}$ and for LIGACLIPs it was only $4 \pm 1.1$ min thus decreasing the overall operative time of the procedure $(p>0.001)$ which was significant. Drain was removed when the volume decreased to $<20 \mathrm{ml} / 24$ hours and colour of the discharge becomes light serous. Only in three cases there was bile in the discharge which remains only for four days. The mean operative time less in whom cystic artery and duct was closed with titanium clips as compared to the silk ligature which was significant. There were no major differences seen in both groups in terms of inpatient stay, post-operative complications and safety of the procedure (Table 1 and 2). Hospital stay in both groups was same i.e. 2 to 3 days. Ryle's tube was removed in evening on same day of surgery. On next day patient was allowed orally sips of water and by evening full diet and planned for discharge on $2^{\text {nd }}$ day of surgery. In four cases hospital stay was three to four days. The ligation with suture needs more expertise than the clip application. Silk has the more advantageous over the clip, as it will be cost-effective, economical and available freely especially in rural area. So, the surgeon should be well versed with both methods. All patients observed post-operatively for any fever, wound infection, haemorrhage, any intra-abdominal collection and the length of stay in hospital. There were no major complications seen in both groups. Patients were followed for two weeks and would be inquired about fever, vomiting, scar pain or any collection inside the abdomen. We compared the results of both studies in view of efficacy, safety, complications, cost-effectiveness and hospital stay. In both studies there were no complications seen except for the little prolonged timing in group A as compared to other group.

\begin{tabular}{|c|c|c|}
\hline Pre-Operative Parameters & Group A & Group B \\
\hline Number of cases & 60 & 60 \\
\hline Male/Female & $24 / 36$ & $23 / 37$ \\
\hline Indications of gall stones & 60 & 60 \\
\hline Pre-op USG & 60 & 60 \\
\hline Table 1. Pre-operative Parameters \\
\hline
\end{tabular}

\begin{tabular}{|c|c|c|}
\hline $\begin{array}{c}\text { Intraoperative Parameters and } \\
\text { Post-Operative Data }\end{array}$ & Group A & Group B \\
\hline Operative time (range) in minutes & $30-50$ & $30-40$ \\
\hline $\begin{array}{c}\text { Operative time (mean } \pm \text { SD) in } \\
\text { minutes }\end{array}$ & $40 \pm 9.8$ & $35 \pm 10.3$ \\
\hline $\begin{array}{c}\text { Closure time for cystic duct and } \\
\text { artery (mean } \pm \text { SD) in minutes }\end{array}$ & $6.5 \pm 1.3$ & $4 \pm 1.1$ \\
\hline Drainage in ml & $45 \mathrm{ml}$ & $40 \mathrm{ml}$ \\
\hline Hospital stay in days & 2 & 2 \\
\hline Complications & 0 & 0 \\
\hline Table 2. Intraoperative Parameters and Post-Operative \\
Data
\end{tabular}

\section{DISCUSSION}

Surgery performed under general anaesthesia and patient kept in the supine position with 30-degree head up and right lateral side elevated. The surgeon and the camera assistant stood on the left side of the patient. In both groups 4 ports were used, $10 \mathrm{~mm}$ for infraumbilical, epigastrium and $5 \mathrm{~mm}$ port for other two ports. After dissecting Calot's triangle, a proper exposure of cystic artery and cystic duct was made.

Cystic duct (CD) exposed distally up to gallbladder and proximally up to the common bile duct. In group A, CD and artery was ligated with non-absorbable suture silk no-2-0 intracorporeally in a surgeon's knot configuration, whereas in group B, titanium LIGACLIPs of sizes large and medium were applied for CD and artery respectively. In both groups, $\mathrm{CD}$ and artery closed separately. We also emphasize on the technique used for closure of the cystic duct with clip, two clips applied on the proximal part of the $\mathrm{CD}$ and one clip used on distal side. If space is less or CD is shorter, in these cases we applied clip obliquely away from the common bile duct. In group A, silk was tie applied and assured that it should not be loose to prevent any leakage. Another advantage of silk is that, it can be tied close to the common bile duct (CBD). Drain will be kept in all the patients in sub hepatic area.

LC has a high degree of safety, but it is important to remember that it is a major operation and should never be undertaken lightly. Literatures suggest that, the incidence of biliary injury is roughly two per 1, 000 open operations for gall stones (Bismuth, 1982). Bile duct injuries have been highlighted with the introduction of LC (Pleass and Garden, 1998). The incidence of bile duct injuries associated with LC is higher than that associated with $\mathrm{OC}$, but should decrease with the surgeon's experience. Unfortunately, many iatrogenic injuries go unrecognized until they cause complications from delayed stricture formation. (Sachdeva et al, 2000).

In recognition of this, Bismuth (1982) has developed a classification of benign bile duct strictures based on the anatomic pattern of involvement. Bismuth classified benign bile duct strictures or injuries into 5 types. He classified them as; type 1 : hepatic duct stump $>2 \mathrm{~cm}$, type 2 : hepatic duct stump. The use of the Bismuth classification appears to be an accurate and practical method for the grading of 
postoperative bile duct lesions with cholangiography (Chartrand-Lefebvre et al 1994)

Risk factors in postoperative bile duct injuries are Fibrosis in the triangle of Calot, acute cholecystitis, obesity, local haemorrhage, variant anatomy, and fat in the porta hepatis were identified as risk factors for bile duct injuries (Asbun et al, 1993). Moossa et al (1990), just before the widespread use of LC, reported similar risk factors as well as inadequate length of incisions (Especially in obese patients) and failure to obtain intra-operative cholangiography. Variations in vascular supply also present potentially dangerous situations, not only from the risk of inadvertently dividing the hepatic arterial supply but also from increasing the likelihood of haemorrhage and obscuring of the operative field (Martin and Rossi, 1994).

Bile leak may be classified into a minor leak with low output drainage $(<300 \mathrm{ml}$ of bile/24 hours) or leaks due to major bile duct injury with high output drainage $(>300 \mathrm{ml} / 24$ hours). Cholecystectomy is the commonest cause of bile leak; it may also be a complication of any bilioenteric anastomosis, percutaneous interventions, abdominal trauma or liver resections. A leak from the cystic duct stump may occur from clip failure due to necrosis of the stump secondary to thermal injury/pressure necrosis or when clips are used in situations where ties are appropriate (Acute cholecystitis) and in a significant majority from distal bile duct obstruction caused by a retained stone and resultant blow out of the cystic stump.

\section{CONCLUSIONS}

In our study, the mean operative time in group $\mathrm{A}$ was $30-50$ minutes and in group B it was $30-40$ minutes $(p=0.015)$. The time required for suture ligation was $6.5 \pm 1.3 \mathrm{~min}$ and for LIGACLIPs it was only $4 \pm 1.1 \mathrm{~min}$ thus decreasing the overall operative time of the procedure $(p<0.001)$. We observed that silk suture is safe, cost effective but it required training as compared to clip application. But for clip application clip applicator is required which is costly. There may be chances of slippage of clips or it may cause stricture formation if it involved the wall of the CBD, though in our study, we have not encountered such complications.

\section{REFERENCES}

[1] Gossage JA, Forshaw MJ. Prevalence and outcome of litigation claims in England after laparoscopic cholecystectomy. Int J Clin Prac 2010;64(13):1832-5.

[2] McMahon AJ, Fullarton G, Baxter JN, et al. Bile duct injury and bile leakage in laparoscopic cholecystectomy. Br J Surg 1995;82(3):307-13.

[3] Strasberg SM, Hertl M, Soper NJ. An analysis of the problem of biliary injury during laparoscopic cholecystectomy. J Am Coll Surg 1995;180(1):101-25.
[4] Shea JA, Healey MJ, Berlin JA, et al. Mortality and complications associated with laparoscopic cholecystectomy. A meta-analysis. Ann Surg 1996;224(5):609-20.

[5] Targarona EM, Marco C, Balagué C, et al. How, when, and why bile duct injury occurs. A comparison between open and laparoscopic cholecystectomy. Surg Endosc 1998;12(4):322-6.

[6] Lillemoe KD, Melton GB, Cameron JL, et al. Postoperative bile duct strictures: management and outcome in the 1990s. Ann Surg 2000;232(3):430-41.

[7] Gazzaniga GM, Filauro M, Mori L. Surgical treatment of iatrogenic lesions of the proximal common bile duct. World J Surg 2001;25(10):1254-59.

[8] Savar A, Carmody I, Hiatt JR, et al. Laparoscopic bile duct injuries: management at a tertiary liver center. Am Surg 2004;70(10):906-9.

[9] Moore DE, Feurer ID, Holzman MD, et al. Long-term detrimental effect of bile duct injury on health-related quality of life. Arch Surg 2004;139(5):476-81.

[10] Misra S, Melton GB, Geschwind JF, et al. Percutaneous management of bile duct strictures and injuries associated with laparoscopic cholecystectomy: a decade of experience. J Am Coll Surg 2004;198(2):21826.

[11] Woods MS, Traversp LW, Kozarek RA, et al. Characteristics of biliary tract complications during laparoscopic cholecystectomy: a multi-institutional study. Am J Surg 1994;167(1):27-33, discussion 33-4.

[12] Schulze S, Damgaard B, Jørgensen LN, et al. Cystic duct closure by sealing with bipolar electrocoagulation. JSLS 2010;14(1):20-2.

[13] Torres K, Chrościcki A, Golonka A, et al. The course of the cystic artery during laparoscopic cholecystectomy. Folia Morphol (Warsz) 2009;68(3):140-3.

[14] Oruc MT, Ugurlu MU, Boyacioglu Z. Transumbilical multiple-port laparoscopic cholecystectomy using standard laparoscopic instruments. Minim Invasive Ther Allied Technol 2012;21(6):423-8.

[15] Wills E, Crawford G. Clipless versus conventional laparoscopic cholecystectomy. J Laparoendosc Adv Surg Tech A 2013;23(3):237-9.

[16] Bulus H, Basar 0, Tas A, et al. Evaluation of three instruments for laparoscopic cholecystectomy: harmonic scalpel, bipolar vessel sealer and conventional technique. Minerva Chir 2013;68(6):53742.

[17] Hasala P. Rates of complications after laparoscopic cholecystectomy depending on the coagulation technique-a comparative study. Rozhl Chir 2012;91(3):158-63. 